\title{
Dermatitis flagelada en paciente VIH positivo con linfoma de Hodgkin
}

Flagellate dermatitis in an HIV patient with Hodgkin lymphoma

\section{Diana Alejandra Sandoval', John Elkin Pedraza²,José Ricardo Ruiz ${ }^{3}$}

1. Residente de Dermatología, Fundación Universitaria Sanitas, Hospital Universitario Centro Dermatológico “Federico Lleras Acosta”, E.S.E., Bogotá D.C., Colombia

2. Residente de Dermatología, Fundación Universitaria Sanitas, Hospital Universitario Centro Dermatológico “Federico Lleras Acosta”, E.S.E., Bogotá D.C., Colombia

3. Médico Dermatólogo, Universidad del Bosque, Bogotá D.C., Colombia

\section{RESUMEN}

La dermatitis flagelada es una reacción cutánea que se asocia frecuentemente al uso de medicamentos como la bleomicina, un agente quimioterapéutico utilizado en el tratamiento de los trastornos linfoproliferativos y de los tumores de células germinales. La incidencia de la dermatitis flagelada varía entre el $8 \%$ y el $22 \%$ en la población mundial que recibe bleomicina; sin embargo, se desconocen los datos de prevalencia e incidencia en pacientes VIH positivos. Se presenta un paciente VIH positivo con linfoma de Hodgkin, quien consultó por aparición de lesiones cutáneas relacionadas con el inicio del tratamiento con bleomicina.

PALABRAS CLAVE: bleomicina, quimioterapia, reacción adversa al medicamento.

\section{SUMMARY}

Flagellated dermatitis is frequently associated with adverse reactions to drugs such as bleomycin, a chemotherapeutic agent, used in the treatment of lymphoproliferative disorders and germ cell tumors. The worldwide incidence of flagellated dermatitis is $8 \%$ to $22 \%$ in the population receiving bleomycin, however, the prevalence and incidence data in HIV positive patients are unknown, and there are only a few case reports in the scientific literature. We present an HIV positive patient with Hodgkin lymphoma who consulted for the appearance of skin lesions related to the initiation of treatment with bleomycin.

KEY WORDS: Bleomycin, chemotherapy, adverse drug reaction.

\section{PRESENTACIÓN DEL CASO}

Varón de 47 años, VIH positivo, en tratamiento desde hace 9 años con esquema antirretroviral y diagnóstico de linfoma de Hodgkin estadio IIA, en manejo con ciclos de doxorrubicina $40 \mathrm{mg}$, bleomicina $12 \mathrm{UI}$, dacarbazina $630 \mathrm{mg}$ y vinblastina $10 \mathrm{mg}$, intravenosos, quien consultó por aparición de un "brote" urente, permanente, ocasionalmente pruriginoso en el cuello, el tórax y la espalda, posterior al primer ciclo de la quimioterapia. En el examen físico se observaron placas pardoeritema-
Correspondencia:

Alejandra Sandoval Clavijo

Email:

alesancla@hotmail.com

Recibido: 17/06/19

Aceptado: 27/10/19

Conflictos de interés:

No se reportan conflictos de interés.

Financiación:

Ninguna. 
tosas, descamativas de distribución lineal en la región superior del tórax (figura 1), para lo cual se indicó desonida en crema al 0,1\% por 15 días con resolución inicial y reaparición de las lesiones luego de la segunda sesión de quimioterapia. Se solicitó biopsia que evidenció espongiosis y ortoqueratosis sobre la dermis, con edema superficial e infiltrado linfohistiocitario (figura 2). Se indicó clobetasol en crema al 0,05\% con mejoría de las lesiones y posterior cambio del esquema de quimioterapia, sin reaparición de estas. En la consulta de control un mes después, se observaron máculas residuales (figura 3).
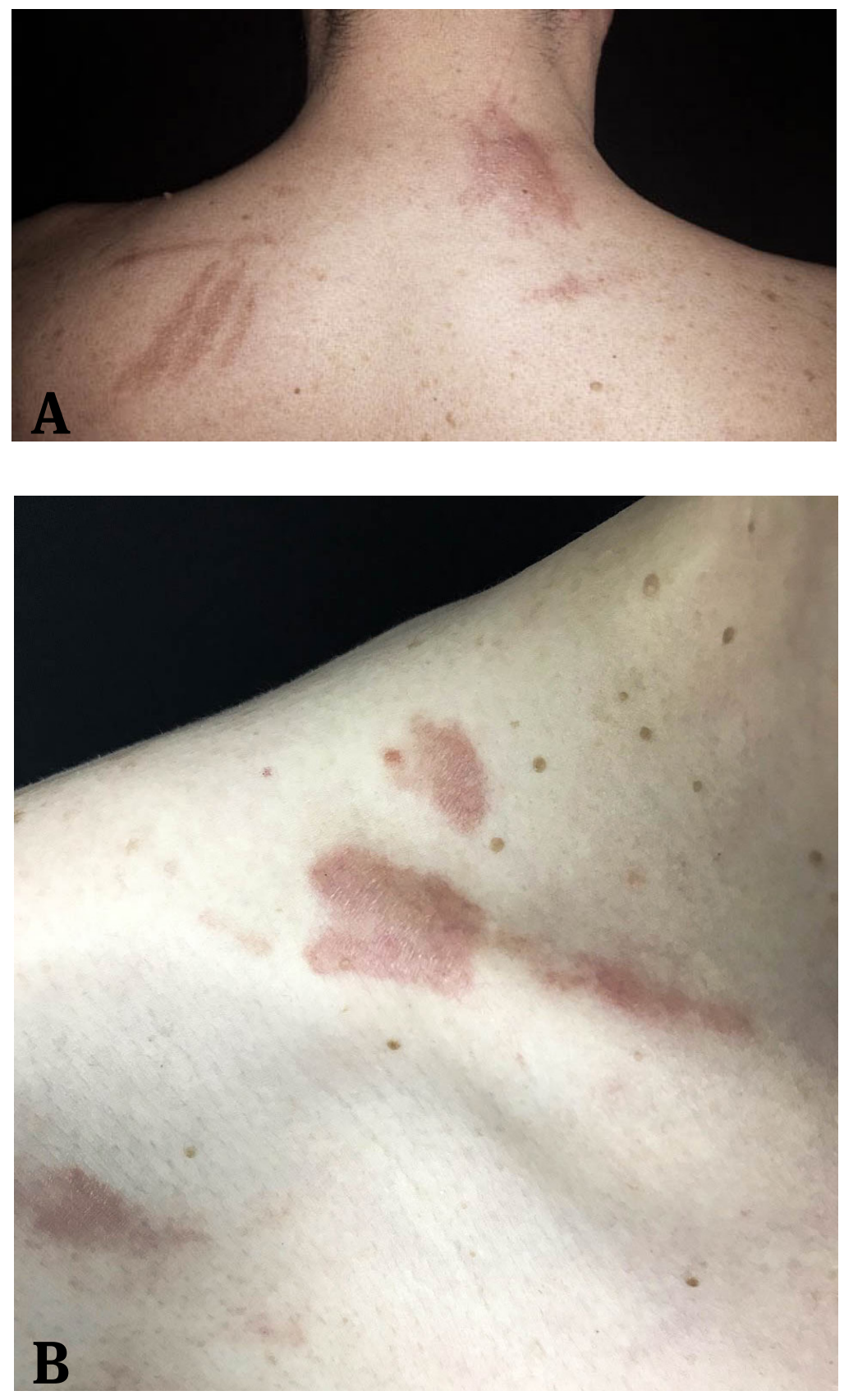

Figura 1. A y B) Placas pardoeritematosas descamativas lineales. A) Región dorsal superior. B) Región clavicular derecha. 


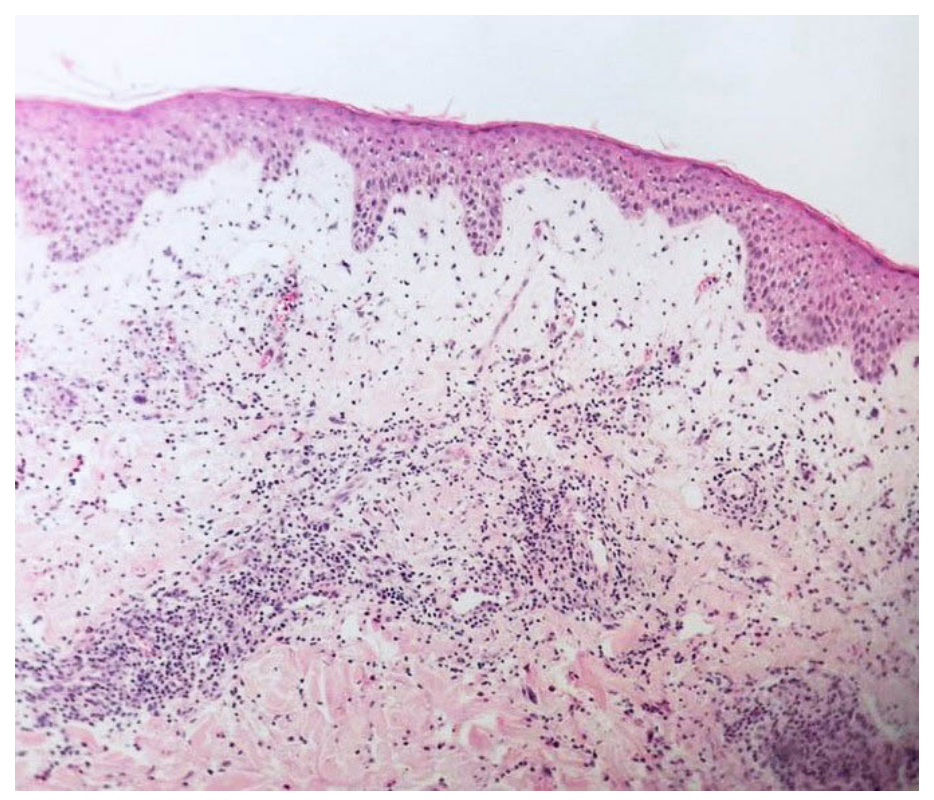

Figura 2. Biopsia de la piel de la espalda. Infiltrado linfohistiocitario perivascular superficial y profundo con algunos eosinófilos. HE 10x.

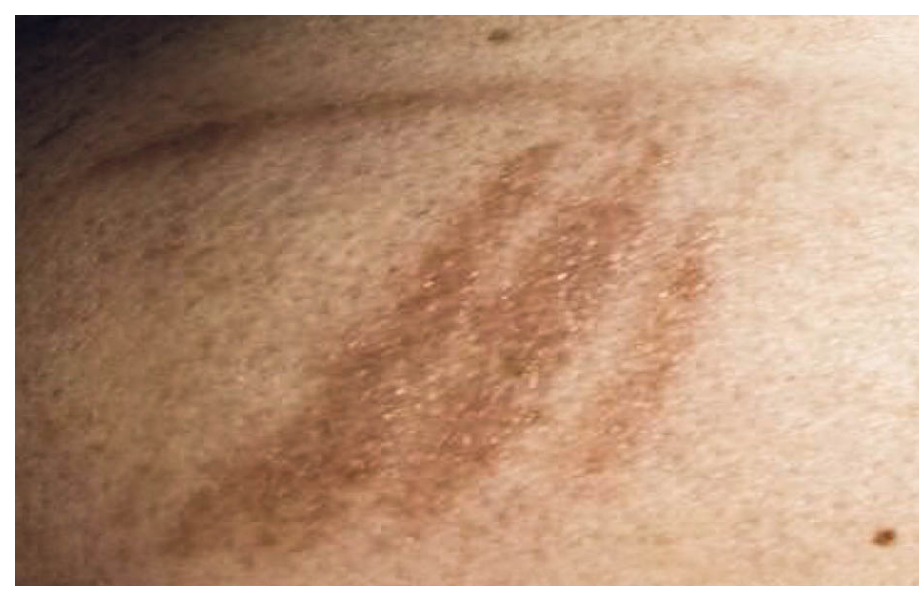

Figura 3. Máculas hiperpigmentadas lineales residuales un mes después de suspender la bleomicina.

\section{DISCUSIÓN}

La dermatitis flagelada es una manifestación cutánea infrecuente asociada a la ingesta de hongos shiitake o medicamentos como el docetaxel, la bendamustina y la bleomicina, en este último caso independiente de la dosis y la vía de administración ${ }^{(1-3)}$. Se ha reportado que esta reacción adversa al medicamento puede ser desencadenada por dosis de bleomicina que varían entre 14 y 100 UI ${ }^{(2,4,5)}$, dosis similar a la utilizada en el tratamiento de este paciente.

El mecanismo patogénico de la enfermedad no ha sido completamente descrito; sin embargo, se ha sugerido que la dermatitis flagelada puede deberse a la reducción en la cantidad de hidrolasa dermoepidérmica inactivadora del medicamento, que provoca su acumulación local e induce la desgranulación de mastocitos 
y la liberación de citocinas proinflamatorias ${ }^{(2,3,6)}$. En pacientes VIH positivo se ha reportado una disminución de los mecanismos antioxidantes del glutatión, lo cual podría incrementar el daño celular producido por los radicales libres en áreas de acumulación de la bleomicina y prolongar el proceso ${ }^{(4,7-9)}$.

Las lesiones consisten en maculoplacas urticariales eritematosas lineales, que resuelven dejando máculas hiperpigmentadas localizadas generalmente en la espalda y el tórax, que aparecen entre el primer día y la novena semana después de la administración del medicamento. Los pacientes pueden presentar prurito de leve a intenso antes de que se produzca la pigmentación ${ }^{(2,5,7)}$. En la histopatología se encuentran cambios inflamatorios inespecíficos, por lo que su sospecha se basa en la historia clínica completa, que incluye los antecedentes farmacológicos, y los hallazgos del examen físico, aunque, en la mayoría de los casos, se observa hipermelanosis y espongiosis de la capa basal, asociados a un infiltrado linfohistiocítico perivascular e incontinencia pigmentaria ${ }^{(2-4)}$.

El tratamiento recomendado es la suspensión de la bleomicina y el cambio del esquema quimioterapéutico y manejo sintomático con antihistamínicos orales y corticosteroides tópicos o sistémicos dependiendo de la extensión y gravedad de las lesiones ${ }^{(4,5)}$.

\section{CONCLUSIONES}

La dermatitis flagelada se caracteriza clínicamente por lesiones similares a las causadas por la flagelación, que ocurren principalmente en el tronco y, en menor proporción, en las extremidades. Su identificación facilita el diagnóstico clínico, especialmente en aquellos pacientes con deficiencias en mecanismos antioxidantes, como ocurre en los pacientes VIH positivos.

\section{REFERENCIAS}

1. Kabel A, Moharm F. Insights into dermatological applications and cutaneous toxicities of bleomycin. M J Derm. 2017;2(1):1-6.

2. Diao YD, Goodall J. Bleomycin-induced flagellate dermatitis. CMAJ. 2012;184(11):1280.

3. Ziemer M, Goetze S, Juhasz K, Elsner P. Flagellate dermatitis as a bleomycin-specific adverse effect of cytostatic therapy: A clinical-histopathologic correlation. Am J Clin Dermatol. 2011;12(1):68-76.
4. Vennepureddy A, Siddique MN, Odaimi M, Terjanian T. Bleomycin-induced flagellate erythema in a patient with Hodgkin's lymphoma - A case report and review of literature. J Oncol Pharm Pract. 2015;22(3):556-60.

5. Schummer C, Winkler Y, Tittelbach J, Grimm MO, Elsner P. Flagellanten-Dermatitis nach Bleomycingabe bei einem Patienten mit malignem Keimzelltumor. Dtsch Med Wochenschr. 2014;139(3):84-6.

6. Kruk D, Sawka C. Bleomycin dermatologic toxicity in a patient with HIV-associated sarcoma. Can J Hosp Pharm. 1997;50(2):77-8.

7. Eungdamrong J, McLellan B. Flagellate erythema. Dermatol Online J. 2013;19(12):20716.

8. Soto Febles C, Febles Fernández C, Saldaña Bernabeu A, García Triana BE. Fenómenos oxidativos asociados con la infección por VIH/Sida. Rev Cuba Invest Biomed. 2002;21(3):201-6.

9. Pomier O, Gil L, Rodríguez F, Huetes L, Alerm A, Bermúdez A, et al. Indicadores del estrés oxidativo en pacientes afectados por VIH/sida con manifestaciones reumatológicas. Rev Cubana Farm. 2012;46(3):329-42. 